\title{
Avaliação das silagens do sorgo BRS-610 em sete estádios de maturação pela técnica in vitro semiautomática de produção de gases
}

\author{
[Evaluation of the silages of sorghum BRS-610 at seven stages of maturation \\ by semi-automated in vitro gas production technique] \\ W.G. Faria Júnior ${ }^{1}$, L.C. Gonçalves ${ }^{2 *}$, R.M. Maurício $^{3}$, J.A.S. Rodrigues ${ }^{4}$, \\ J.C.N. Colodo ${ }^{1}$, W.G. Faria ${ }^{1}$, L.F. Souza ${ }^{1}$ \\ ${ }^{1}$ Aluno de pós-graduação - EV-UFMG - Belo Horizonte, MG \\ ${ }^{2}$ Escola de Veterinária - UFMG \\ Av. Antônio Carlos, 6627 \\ 31270-901 - Belo Horizonte, MG \\ ${ }^{3}$ Universidade Federal de São João del Rei - São João del Rei, MG \\ ${ }^{4}$ Embrapa Milho e Sorgo - Sete Lagoas, MG \\ RESUMO
}

\begin{abstract}
Avaliou-se a qualidade da silagem do sorgo BRS-610 produzida em sete estádios de maturação dos grãos, pela técnica in vitro semiautomática de produção de gases. O delineamento foi inteiramente ao acaso, com quatro repetições por tratamento, e as médias foram comparadas pelo teste Scott-knott. Os parâmetros potencial máximo de produção de gases, tempo de colonização, taxa de produção de gases e degradabilidade efetiva da matéria seca para as taxas de passagem de 2,5 e $8 \% / \mathrm{h}$ foram obtidos pelo modelo de France et al. O potencial máximo de produção de gases não diferiu entre as silagens e indicou média de 170,5mL/g de matéria seca. Entre leitoso/pastoso e pastoso houve menor tempo de colonização. As maiores taxas de fermentação foram observadas nas silagens produzida entre os estádios pastoso/farináceo a seco. As degradabilidades efetivas foram semelhantes entres as silagens, com média de 46,2\%. O sorgo BRS-610 produziu silagem de qualidade satisfatória, com destaque para a silagem produzida com a planta no estádio pastoso/farináceo, por associar melhor taxa de fermentação e menor tempo de colonização.
\end{abstract}

Palavras-chave: sorgo, silagem, produção de gases, valor nutritivo

\begin{abstract}
The quality of the silages of sorghum BRS-610 produced at seven stages of grain maturation was evaluated by the semi-automatic gas production technique. It was used a complete randomized design, with four repetitions per treatment, and the means were compared by the Scott-knott test $(P<0.05)$. The potential of production of gases, lag phase, rates of gas production, and effective dry matter degradability for 2, 5, and 8\%/h rates of passage were obtained by the model of France et al. The potential of gas production did not differ among the silages, showing mean of $170.5 \mathrm{~mL} /$ dry matter. The stages between milky/soft dough to soft dough showed shorter lag phase. The highest rate of gas production was observed in the silages produced between soft dough/floury to dry stages. The effective degradabilities were similar among the silages, averaging 46.2\%. The sorghum BRS-610 produced satisfactory quality silage, mainly for the silage produced with the plant at soft dough/floury stage, for associating better rate of gas production and shorter lag phase.
\end{abstract}

Keywords: sorghum, silage, gas production, nutritional value

Recebido em 14 maio de 2009

Aceito em 12 de julho de 2010

*Autor para correspondência (corresponding author)

E-mail: luciocg@vet.ufmg.br 


\section{INTRODUÇÃO}

O sorgo BRS-610, obtido pela Embrapa pelo cruzamento do material CMSXS 232A $\mathrm{x}$ CMSXS 234R, destaca-se pela resistência moderada a doenças como antracnose e ferrugem, e pela boa resistência à helmintosporiose. O BRS-610 é um sorgo de colmo seco, de grãos com endosperma semiduro e sem tanino. Observa-se, ainda, boa resistência ao acamamento, o que favorece a colheita mecanizada, com mínimas perdas a campo e resistência à acidez do solo (Rodrigues et al., 2004). Contudo, necessita-se avaliar o valor nutricional de sua silagem e o melhor momento de colheita.

A qualidade nutricional de uma forrageira é medida por sua digestibilidade e pelo consumo voluntário. No entanto, as avaliações desses parâmetros in vivo são técnicas laboriosas, caras e demoradas, que dificultam a avaliação de alimentos. Dessa forma, a utilização de técnicas laboratoriais para predição de consumo e digestibilidade tem sido uma opção para avaliação do valor nutricional de alimentos de uma maneira mais prática e rápida (Getachew et al., 1998).

A técnica de produção de gases in vitro apresenta algumas vantagens quando comparada com a técnica in vitro de Tilley e Terry (1963). Os métodos in vitro são baseados em medidas gravimétricas do desaparecimento de componentes que nem sempre contribuem para fermentação e produção de gases. Além disso, na metodologia de produção de gases, a cinética de fermentação pode ser avaliada em uma única amostra utilizando-se uma pequena quantidade de material. A técnica in vitro semiautomática de produção de gases (Maurício et al., 1999), ou Reading Pressure Technique (RPT), tem a capacidade de avaliar grande número de substratos e descrever a cinética de fermentação ruminal.

A técnica apresenta potencial de descrição da cinética de fermentação, da taxa e extensão da degradação de forrageiras (Guimarães Jr. et al., 2008). Constitui também uma ferramenta promissora em avaliações das taxas de digestão das frações solúveis e insolúveis dos alimentos, utilizadas pelos sistemas modernos de predição de consumo (Nutrient..., 1996; 2001). A técnica in vitro semiautomática de produção de gases apresenta a vantagem de permitir a avaliação de um grande número de amostras por experimento, com boa acurácia, facilidade de manuseio e baixo custo por amostra analisada.

O objetivo deste experimento foi determinar o valor nutricional das silagens do sorgo BRS-610 em sete estádios de maturação, por meio da avaliação da produção de gases e da degradabilidade da matéria seca, utilizando-se a técnica in vitro semiautomática de produção de gases.

\section{MATERIAL E MÉTODOS}

O híbrido de sorgo BRS-610 foi cultivado, colhido e ensilado na Embrapa Milho e Sorgo no ano agrícola de 2004/2005. O material foi semeado em canteiros de 7 x 3,5m, com espaçamento entre linhas de $0,70 \mathrm{~m}$. O sorgo foi plantado em 26 de novembro de 2004, com o florescimento ocorrendo em 16/02/2005 aos 82 dias de idade da planta, e os cortes foram realizados em intervalos de sete dias, nas datas a seguir: 02/03/2005, 09/03/2005, 16/03/2005, 23/03/2005, 30/03/2005, 06/04/2005, $13 / 04 / 2005$. Os cortes correspondem a oito estádios de maturação da planta - E1, E2, E3, E4, E5, E6 e E7 - , conforme descrito na Tab.1.

Tabela 1. Estádios de maturação do sorgo BRS-610

\begin{tabular}{cccc} 
Dias pós-plantio & $\begin{array}{c}\text { Dias } \\
\text { pós-florescimento }\end{array}$ & $\begin{array}{c}\text { Estádio } \\
\text { de maturação }\end{array}$ & $\begin{array}{c}\text { Estádios } \\
\text { dos grãos }\end{array}$ \\
\hline 96 & 14 & E1 & Leitoso \\
103 & 21 & E2 & Leitoso/pastoso \\
110 & 28 & E3 & Pastoso \\
117 & 35 & E4 & Pastoso/farináceo \\
124 & 42 & E5 & Farináceo \\
131 & 49 & E6 & Duro \\
138 & 56 & E7 & Seco \\
\hline
\end{tabular}


As plantas, cortadas manualmente rente ao solo, em duas linhas centrais, com descarte de $1 \mathrm{~m}$ nas extremidades dos canteiros, foram imediatamente picadas em picadeira estacionária. O material foi amostrado de forma homogênea, ensilado em silos experimentais de laboratórios fechados com tampas de PVC dotadas de válvula do tipo Bunsen. A abertura dos silos foi realizada aos 56 dias de fermentação. Amostras das silagens foram pré-secas a $55^{\circ} \mathrm{C}$ durante 72 horas, moídas a $1 \mathrm{~mm}$ e armazenadas em recipientes de polietileno para posterior avaliação pela técnica in vitro semiautomática de produção de gases (Maurício et al., 1999).

$\mathrm{Na}$ avaliação da qualidade nutricional das silagens pela técnica in vitro semiautomática de produção de gases, $1 \mathrm{~g}$ de amostra foi adicionado aos frascos de fermentação $(160 \mathrm{~mL})$ previamente injetados com $\mathrm{CO}_{2}$. Foram utilizados três frascos por repetição. Frascos contendo somente líquido ruminal e meio de cultura (tampão) foram usados como controle. Para cada frasco, foram adicionados manualmente, utilizando-se uma proveta, $90 \mathrm{~mL}$ de meio de cultura, conforme Theodorou et al. (1994).

O líquido ruminal foi obtido de um bovino macho castrado, de raça europeia, fistulado, mantido em dieta à base de volumoso (feno de Tyfton 85) à vontade e $3 \mathrm{~kg}$ de concentrado comercial por dia (20\% de PB). O líquido ruminal foi retirado pela manhã, antes da alimentação do animal, e armazenado em garrafas térmicas previamente aquecidas. No laboratório, o líquido ruminal foi filtrado sob injeção contínua de $\mathrm{CO}_{2}$ e mantido em banhomaria a $39^{\circ} \mathrm{C}$. A inoculação foi realizada sob injeção de $10 \mathrm{~mL}$ do líquido ruminal por frasco com uma seringa plástica conectada a uma agulha $(0,6 \mathrm{~mm})$.

As leituras de pressão foram tomadas em maior frequência durante $\mathrm{o}$ período inicial de fermentação e reduzidas posteriormente (duas, quatro, seis, oito, dez, 12, 15, 19, 24, 30, 36, 48 72, e 96h). A partir da inserção da agulha na tampa de borracha, a pressão produzida no interior dos frascos foi lida no leitor digital. Os dados de pressão foram utilizados para o cálculo do volume de gases produzidos, por meio de equação matemática desenvolvida por Maurício et al. (2003a).
Os resíduos de fermentação foram obtidos por filtragem em cadinhos de porosidade 1 (pirex vidrotec) previamente pesados. Após filtragem, os cadinhos com o resíduo de degradação foram secados por 48 horas a $100^{\circ} \mathrm{C}$ e pesados para que fossem calculados os valores de degradabilidade da matéria seca após 96 horas de fermentação.

O modelo de France et al. (1993) foi utilizado para descrever o potencial máximo de produção de gases (A), o tempo de colonização (L) e a taxa de produção de gases $(\mu)$, por meio do programa MLP (Ross, 1980).

As degradabilidades efetivas da matéria seca (DEMS), empregando-se as taxas de passagem de 2,5 e $8 \%$ /h para baixo, médio e alto consumo, respectivamente, conforme recomendações do ARC (Report....,1984), foram calculadas pela equação proposta por France et al. (1993), utilizando-se o software MLP (Ross, 1980).

O delineamento utilizado foi o inteiramente ao acaso. Para os dados de produção cumulativa de gases após seis, 12, 24, 48, 72 e 96 horas de fermentação, utilizou-se esquema fatorial $7 \times 6$ (época de corte $\mathrm{x}$ tempo de produção cumulativa de gases) com quatro repetições, descrito pelo modelo estatístico:

$\mathrm{Y}_{\mathrm{ijk}}=\mu+\mathrm{T}_{\mathrm{i}}+\mathrm{A}_{\mathrm{k}}+\left(\mathrm{T}^{*} \mathrm{~A}\right)_{\mathrm{ik}}+\epsilon_{\mathrm{ij}}$, em que:

$Y_{\mathrm{ijk}}=$ observação da variável resposta para $\mathrm{o}$ estádio de maturação i no tempo k no bloco;

$\mu=$ média geral;

$\mathrm{T}_{\mathrm{i}}=$ efeito do estádio de maturação da planta ao corte; i = E2, E3, E4, E5, E6, E7 e E8;

$A_{k}=$ efeito do tempo de incubação; $k=6,12,24$, 48, 72 e 96 horas de incubação;

$\left(\mathrm{T}^{*} \mathrm{~A}\right)_{\mathrm{ik}}=$ efeito da interação estádio de maturação $\mathrm{x}$ tempo de incubação;

$\epsilon_{\mathrm{ij}}=$ erro aleatório atribuído ao estádio de maturação i no tempo de incubação $\mathrm{K} ; \epsilon_{\mathrm{ik}} \cong \mathrm{N}$ $(0,1)$.

Para verificar a normalidade e homocedasticidade de variâncias, utilizaram-se os testes de Lilliefors e Bartlett, respectivamente. A comparação das médias foi feita utilizando-se o teste de agrupamento de Scott-Knott, em nível de $5 \%$ de probabilidade, usando-se o pacote estatístico SAEG (Sistema...; 2007). 


\section{RESULTADOS E DISCUSSÃO}

$\mathrm{Na}$ Tab. 2, encontram-se as produções cumulativas de gases das silagens do híbrido de sorgo BRS-610 em sete estádios de maturação da planta ao corte, após seis, 12, 24, 48, 72 e 96 horas de fermentação.

Não foi observada variação significativa na produção de gases entre os estádios de maturação para um mesmo período de incubação. A comparação entre períodos de incubação para um mesmo estádio de maturação mostrou-se com produções acumuladas de gases crescentes $(\mathrm{P}<0,05)$ até 96 horas de incubação, com as médias de 22,58, 60,79, 103,71, 139,85, 160,01 e $170,66 \mathrm{~mL} / \mathrm{g}$ de MS, para os tempos de incubação seis, 12, 24, 48, 72 e 96 horas, respectivamente. As semelhanças $(\mathrm{P}>0,05)$ para as comparações entre os estádios de maturação impossibilitam destacar as que apresentaram maior fermentação nos distintos tempos de incubação. Contudo, apesar da semelhança estatística, a diferença numérica de menor produção de gases em E7, para os tempos de incubação de 24 a 96 horas, pode ser indicativo de menor fermentação da fração fibrosa lentamente degradável presente nesse material em E7, representado principalmente pelas folhas e pelos colmos.

$\mathrm{Na}$ Fig. 1, podem ser vistas as curvas de produção cumulativa de gases da MS do híbrido BRS-610 nos diferentes estádios de maturação. Destacam-se os valores mais baixos da curva de produção cumulativa de gases em E7 para os tempos de incubação de 24 a 96 horas.

O processo de lignificação dessas partes da planta de sorgo pode ser o responsável pela menor produção de gases nos estádios mais avançados de maturação. Araújo (2006) e Pires (2007) avaliaram a produção de gases de seis híbridos (ATF54*9929036, CMSXS217*9929012, CMSXS206*9930002, BR 601, BR 700 e VOLUMAX) e quatro genótipos (CMSXS165, CMSXS114, BR601 e BR700) de sorgo, colhidos no estádio de grãos leitoso/pastoso e farináceo/duro, respectivamente. Esses autores encontraram médias de produção cumulativa de gases por tempo diferentes entre si: os valores foram de 19,04; 43,30; 89,99; 137,73 e $175,54 \mathrm{~mL} / \mathrm{g}$ de $\mathrm{MS}$ e 19,$485 ; 47,82 ; 86,63$; 142,34 e $176,74 \mathrm{~mL} / \mathrm{g}$ de MS, para os tempos de incubação de seis, 12, 24, 48, 96 horas, respectivamente. Esses valores, em comparação aos do presente estudo, foram inferiores para as primeiras 24 horas de incubação, o que mostra menor tempo de colonização e maior taxa de fermentação para o BRS-610, possivelmente pela disponibilidade de carboidratos solúveis e melhor qualidade da fibra, que favorecem a rápida colonização e o início da degradação da fibra.

Na Fig. 2, mostra-se a produção de gases por hora da matéria seca das silagens, do híbrido de sorgo BRS-610 em sete estádios de maturação. Para todas as silagens, houve um primeiro ponto de elevação de produção de gases, que ocorreu entre seis e 12 horas, possivelmente devido à fermentação de carboidratos prontamente disponíveis, no caso os carboidratos solúveis e o amido presente na panícula da planta do sorgo. $\mathrm{O}$ segundo ponto de elevação de produção de gases, observado também para todas as silagens, ocorrido entre 30 e 48 horas, corresponde à fermentação dos carboidratos fibrosos (hemiceluloses e celulose), pertencentes à parede celular.

Tabela 2. Produções cumulativas de gases (em mL/g de MS) após os tempos de incubação das silagens do sorgo BRS-610 em sete estádios de maturação

\begin{tabular}{ccccccc}
\hline & \multicolumn{7}{c}{ Tempos de incubação (horas) } \\
\cline { 2 - 7 } Estádio de maturação & 6 & 12 & 24 & 48 & 72 & 96 \\
\hline E1 & 26,797 & 57,990 & 100,938 & 139,407 & 160,574 & 171,009 \\
E2 & 31,399 & 70,737 & 108,304 & 142,433 & 162,303 & 172,176 \\
E3 & 24,666 & 67,357 & 105,972 & 141,442 & 162,616 & 172,655 \\
E4 & 18,808 & 60,749 & 108,033 & 144,910 & 165,005 & 174,752 \\
E5 & 22,002 & 64,907 & 110,679 & 149,631 & 169,889 & 181,706 \\
E6 & 18,349 & 55,758 & 102,524 & 140,029 & 160,042 & 171,499 \\
E7 & 16,054 & 48,038 & 89,524 & 121,139 & 139,685 & 150,842 \\
\hline médias & 22,582 & 60,791 & 103,711 & 139,856 & 160,016 & 170,663 \\
\hline
\end{tabular}

Teste Scott-knott $(\mathrm{P}<0,05) . \mathrm{CV}=7,52 \%$.

E1: leitoso; E2: leitoso/pastoso; E3: pastoso; E4: pastoso/farináceo; E5: farináceo; E6: duro; E7: seco. 


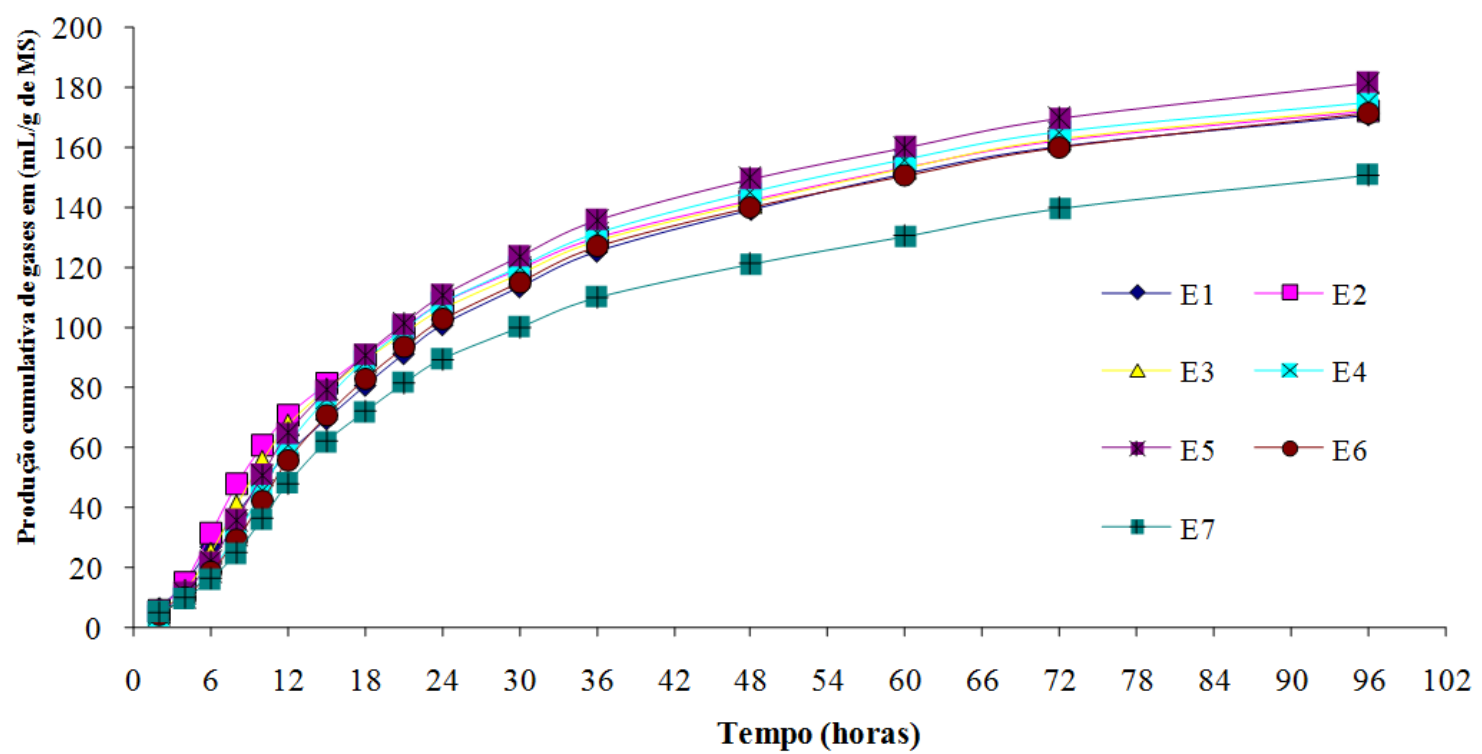

Figura 1. Produção acumulativa de gases das silagens do sorgo BRS-610 em sete estádios de maturação.

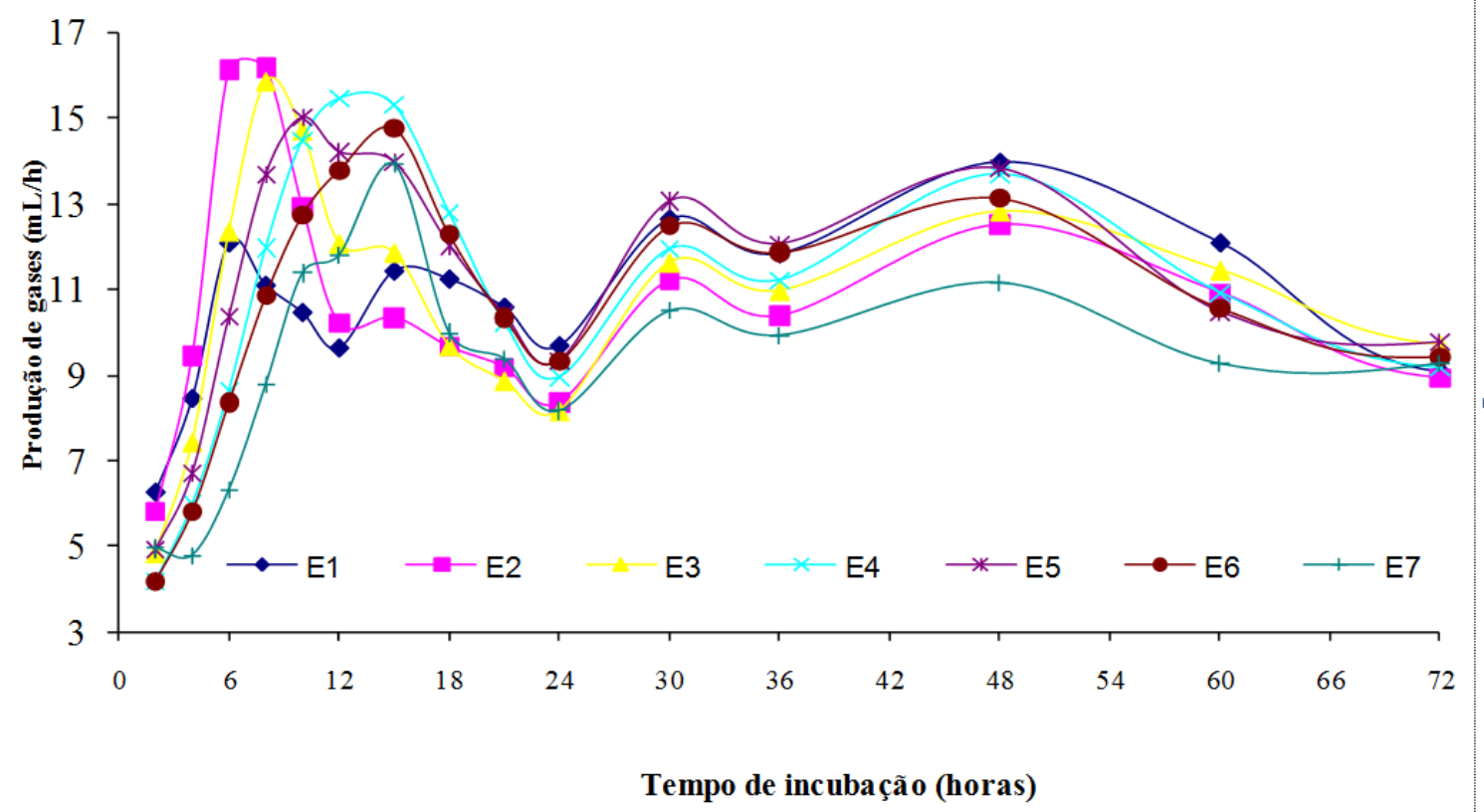

Figura 2. Produção de gases por hora das silagens do híbrido de sorgo BRS-610 em sete estádios de maturação.

As silagens produzidas em E1 e E2 foram as primeiras a alcançar o ponto de elevação de fermentação de carboidratos prontamente fermentáveis, o que ocorreu nas primeiras seis horas de incubação. Observa-se que, com o avanço da maturidade, houve retardo na degradação desses carboidratos. Isso pode ser justificado, em parte, pelo menor acesso das bactérias aminolíticas aos grânulos de amido presente no grão de sorgo, devido ao menor teor de umidade do grão, maior resistência da matriz proteica que recobre os grânulos de amido no endosperma e maior resistência do pericarpo, dificultando a degradação microbiana e, consequentemente, a sua digestão. Para que o amido da região vítrea dos grãos de sorgo se 
torne disponível para a digestão, é necessária a digestão preliminar da parede celular e do arcabouço formado pela matriz proteica e pelos corpos protéicos que recobrem os grânulos de amido. Por isso, é necessária a formação de "consórcios" de microrganismos ruminais para que a digestão dos grãos se processe. Portanto, é necessária a presença de microrganismos celulolíticos e proteolíticos para a digestão daquelas estruturas para que o amido se torne disponível (Orskov, 1986; Antunes, 2005).

O menor ponto de elevação de fermentação para os carboidratos da parede celular foi observado para a silagem produzida em E7. Contudo, para os outros estádios de maturação, os pontos de elevação foram muito próximos. Porém, ao final de 72 horas de incubação, todas as silagens parecem ter atingido o máximo da fermentação da fração fibrosa, revelado pelas menores produções de gases, nesse momento. As produções de gases observadas a partir desse momento indicam fermentações de substrato bacteriano.

Os parâmetros da cinética de produção de gases e degradabilidades efetivas, determinados pelo modelo de France et al. (1993), referentes à matéria seca das silagens em diferentes estádios de maturação do sorgo, encontram-se na Tab. 3.

Tabela 3. Potencial máximo de produção de gases (A) em mL/g de MS, tempo de colonização (TC) em horas, taxa de produção de gases $(\mu) \mathrm{em} \mathrm{mL} / \mathrm{g}$ de $\mathrm{MS} / \mathrm{h}$, degradabilidade efetiva da MS (DEMS) e degradação da MS (DMS) em 96 horas de incubação das silagens do sorgo BRS-610 em sete estádios de maturação da planta

\begin{tabular}{cccccccc}
\hline & \multicolumn{7}{c}{ Estádio de maturação } \\
\cline { 2 - 8 } Parâmetro & E1 & E2 & E3 & E4 & E5 & E6 & E7 \\
\hline A (mL/g de MS) & 175 & 178 & 176 & 171 & 179 & 168 & 147 \\
TC (h:min) & $01: 28$ & $01: 54$ & $01: 03$ & $01: 06$ & $01: 59$ & $02: 00$ & $01: 42$ \\
$\mu(\mathrm{mL} / \mathrm{g}$ de MS/h) & 0,03 & 0,02 & 0,03 & 0,05 & 0,04 & 0,05 & 0,051 \\
\hline DEMS 2,0\%/h (\%) & 33,83 & 25,85 & 27,35 & 29,69 & 30,36 & 30,81 & 30,61 \\
DEMS 5,0\%/h (\%) & 24,57 & 13,73 & 14,78 & 18,56 & 17,98 & 15,67 & 17,03 \\
DEMS 8,0\%/h (\%) & 18,59 & 6,52 & 7,33 & 12,83 & 11,57 & 6,77 & 9,25 \\
\hline DMS 96h $(\%)^{1}$ & 45,03 & 43,035 & 44,33 & 45,29 & 48,53 & 50,35 & 48,34 \\
\hline
\end{tabular}

${ }^{\mathrm{I}}$ Teste Scott-knott $(\mathrm{P}<0,05)$. $\mathrm{CV}=7,52 \%$.

E1: leitoso; E2: leitoso/pastoso; E3: pastoso; E4: pastoso/farináceo; E5: farináceo; E6: duro; E7: seco.

Os potenciais máximos de produção de gases variaram de 147,00 a 179,00mL/g de MS para E7 e E5, respectivamente, mas não foi observada diferença entre os estádios.

O tempo de colonização (TC) representa o tempo compreendido entre o início da incubação até a ação microbiana sobre a amostra testada. A redução no TC é favorecida pela presença de substratos prontamente fermentáveis, ausência de fatores antinutricionais e por características físicas e químicas (como maior ou menor teor de lignina) da parede celular da amostra. Os TC variaram de $1 \mathrm{~h} 3 \mathrm{~min}$ a $2 \mathrm{~h}$, com os menores tempos verificados para as silagens produzidas em E3 (1h3min) e E4 (1h6min), momento em que se observa aumento da fração de panícula e boa qualidade da fibra das frações das folhas. Contudo, com o avanço da maturidade, a redução na qualidade da fibra (elevações nos teores de FDN e FDA) das folhas volta a elevar os tempos de colonização.

As taxas de produção de gases variaram de 0,03 a $0,05 \mathrm{~mL} / \mathrm{g}$ de $\mathrm{MS} / \mathrm{h}$. Houve maior taxa de produção de gases entre E4 e E7, o que confirma o aumento da fração de panículas, cujo amido apresenta maior taxa de fermentação que as frações fibrosas presentes nas folhas e nos colmos. A menor taxa de fermentação em estádios mais imaturos, antes de E5, justifica-se, em parte, pela maior participação das frações de folhas e colmos na MS da planta.

A degradabilidade efetiva da matéria seca (DEMS) foi calculada para taxas de passagem de 2, 5 e $8 \%$ h, conforme recomendações do ARC (Report..., 1984). Segundo o ARC (The 
Nutrient..., 1984), trabalha-se com taxas de passagem de $2,0 \% / \mathrm{h}$ para bovinos e ovinos alimentados para mantença, de $5,0 \% / \mathrm{h}$ para vacas de baixa produção, $15 \mathrm{~kg}$ de leite/dia, e para bovinos de corte e ovinos alimentados com dietas mistas, e de $8,0 \% / \mathrm{h}$ para vacas com média e alta produção de leite, acima de $25 \mathrm{~kg}$ de leite/dia (Tab. 3).

As alterações nas DEMS das silagens, em função dos estádios de maturação, são mais intensas em condições de maior taxa de passagem (5 e $8 \% / \mathrm{h})$. As DEMS na taxa de passagem de $2 \% /$ h tiveram pouca variação com o estádio de maturação, variando de 25,85 a $33,83 \%$. Em situações de taxa de passagem de 5 e $8 \% / \mathrm{h}$, as DEMS reduziram de 24,57 para 13,73 e de 18,59 para $6,52 \%$. Ressalta-se a redução considerável da DEMS entre E1 e E2 para todas as taxas de passagem mencionadas, bem como as reduções observadas em E6 e E7 a uma taxa de passagem de $8 \% / h$

Maurício et al. (2003b), ao avaliarem a produção de gases das silagens de quatro cultivares de sorgo, obtiveram valores de potencial máximo de produção de gases de 179, 179, 194 e $166 \mathrm{~mL} / \mathrm{g}$ de MS, para os híbridos BR700, BR701, BR601 e AG2002, respectivamente. O valor encontrado por esses autores, para os híbridos BR700 e BR701, foi semelhante ao observado neste estudo, e o do BR601, maior que o do presente trabalho. Pires (2007) avaliou a qualidade da silagem de quatro híbridos de sorgo com e sem tanino pela técnica semiautomática de produções de gases. Esse autor, ao avaliar o sorgo BR700, encontrou valores de A $(173 \mathrm{~mL} / \mathrm{g}$ de $\mathrm{MS})$, TC (1h53min), $\mu(0,019 \mathrm{~mL} / \mathrm{g}$ de $\mathrm{MS} / \mathrm{h})$ e DEMS $(29,7,17,8$ e $13,6 \%$, para 2,5 e $8 \% / \mathrm{h})$ semelhantes ao deste trabalho para o mesmo estádio de maturação (farináceo). Por outro lado, Maurício et al. (2003b), ao avaliarem silagens de sorgo, encontraram valores de DEMS acima dos verificados no presente experimento, de 42,5; 30,0 e $23,4 \%$ para o híbrido BR700 e de 47,8; 34,3 e $26,7 \%$ para o híbrido BR601, respectivamente, para as taxas de passagens de 2 , 5 e $8 \% / h$.

De acordo com Tomich (2003), partindo do princípio de que os gases produzidos refletem a degradação da amostra testada, a taxa e o potencial máximo de produção de gases são, provavelmente, os principais parâmetros para avaliar a qualidade de forrageiras testadas pela técnica de produção de gases. Assim, forrageiras mais fermentáveis ou digestíveis seriam aquelas que apresentam maiores valores de potencial máximo associado à alta taxa de produção de gases, resultando numa maior fermentação do material em menor tempo de incubação. Seguindo esses parâmetros, a silagem produzida em E4 sobressai por associar melhor taxa de fermentação e menor tempo de colonização, uma vez que os valores de potencial máximo de produções de gases foram semelhantes.

\section{CONCLUSÕES}

O sorgo BRS-610 produziu silagens de qualidade satisfatória, com destaque para as silagens produzidas em E4 (grãos pastoso/farináceo), por associar melhor taxa de fermentação e menor tempo de colonização, uma vez que os valores de produção cumulativa e potencial máximo de produções de gases foram semelhantes entre os estádios de maturação avaliados.

\section{REFERÊNCIAS BIBLIOGRÁFICAS}

ANTUNES, R.C. Valor nutritivo de grãos de sorgo com diferentes texturas do endosperma para animais. 2005. 110p. Tese (Doutorado) Escola de Veterinária, Universidade Federal de Minas Gerais, Belo Horizonte.

ARAÚJO, V.L. Características agronômicas $e$ avaliação de silagens de 25 híbridos de sorgo. 2006, 80p. Tese (Doutorado). - Escola de Veterinária, Universidade Federal de Minas Gerais, Belo Horizonte.

FRANCE, J.; DHANOA, M.S.; THEODOROU, M.K. et al. A model to interpret gas accumulation profiles associated with in vitro degradation of ruminant feeds. J. Theor. Biol., v.163, p.99-111, 1993.

GETACHEW, G.; BLÜMMEL, M.; MAKKAR, H.P.S. et al. In vitro gas measuring techniques for assesment of nutritional quality of feeds: a review. Anim. Feed Sci. Technol., v.72, p.261281, 1998.

GUIMARÃES Jr., R.; GONÇALVES, L.C.; MAURÍCIO, R.M. et al. Cinética de fermentação ruminal de silagens de milheto. Arq. Bras. Vet. Zootec., v.60, p.1174-1180, 2008. 
MAURÍCIO, R.M.; MOULD, F.L.; DHANOA, M.S. et al. A semi-automated in vitro gas production technique for ruminant feedstuff evaluation. Anim. Feed Sci. Techol., v.79, p.321330, 1999.

MAURÍCIO, R.M.; PEREIRA, L.G.R.; GONCALVES, L.C. et al. Relação entre pressão e volume para implantação da técnica in vitro semiautomática de produção de gases na avaliação de forrageiras tropicais. Arq. Bras. Med. Vet. Zootec., v.55, p.216-219, 2003a.

MAURÍCIO, R.M.; PEREIRA, L.G.R.; GONCALVES, L.C. et al. Potencial da técnica in vitro semiautomática de produção de gases para avaliação de silagens de sorgo (Sorghum bicolor (L.) Moench). Rev. Bras. Zootec., v.32, p.1013$1020,2003 b$

NUTRIENT requirements of beef cattle. 7.ed. Washington: National Academy of Science, 1996. 359p.

NUTRIENT requirements of dairy cattle.7.ed.rev. Washington: National Academy of Science, 2001. 408p.

ORSKOV, E.R. Starch digestion and utilization in ruminants. J. Anim. Sci., v.63, p.1624-1633, 1986.

PIRES, D.A.A. Avaliação de quatro genótipos de sorgo (Sorghum bicolor) com e sem taninos nos grãos para a produção de silagem. 2007, 105f. Tese (Doutorado) - Escola de Veterinária, Universidade Federal de Minas Gerais, Belo Horizonte.
REPORT of the protein group of the Agricultural Research Council Working party, on the nutrient of ruminants. London: Comlonwealth Agricultural Bureaux, 1984. 45p.

ROSS, G.J.S. Maximun Likelihood Program (A Manual). Hampendon: Tothmsted Experimental Station, 1980.

SISTEMA para análises estatísticas - SAEG. Versão 9.1. Viçosa: UFV, 2007.

RODRIGUES, J.A.S.; SANTOS, F.G.; SHAFFERT, R.E. et al. BRS-610 - híbrido de sorgo forrageiro para produção de silagem de alta qualidade. Sete Lagoas: Embrapa Milho e Sorgo, 2004. (comunicado técnico, 102).

THEODOROU, M.K.; WILLIANS, B.A.; DHANOA, M.S. et al. A new gas prodution method using a pressure transducer to determine the fermentation kinetics of ruminal feeds. Anim. Feed Sci. Technol., v.48, p.185-197, 1994.

THE NUTRIENT requeriments of ruminant livestock - ARC., suppl.1. Slough: Comlonwealth Agricultural Bureaux, 1984. 45p.

TILLEY, J.M.A.; TERRY, R.A. A two-stage technique for the in vitro digestion of forage crops. J. Br. Grass. Soc., v.18, p.104-111, 1963.

TOMICH, T.R. Potencial forrageiro de híbridos de sorgo com capim-sudão avaliados em regime de corte. 2003. 82f. Tese (Doutorado) - Escola de Veterinária, Universidade Federal de Minas Gerais, Belo Horizonte. 